patients have also revealed unmet needs for physical care (Brugha et al, 1989; Honig et al, 1989). However, some problems, particularly smoking and obesity, are not very amenable to intervention.

Providing primary care to a high-dependency group home is a challenging task but one which I have found rewarding and never boring. The difficulties in providing a high level of care to such disabled residents and support to the staff should not be underestimated, and should be recognised by way of remuneration in addition to the usual fees for general medical services.

\section{References}

ALLEBECK, P. (1989) Schizophrenia: a life-shortening disease. Schizophrenia Bulletin, 16, 81-89.
ALLEN, D. (1992) The relationship between hospital hostels in the community and the general practitioners who look after them. Psychiatric Bulletin, 16, 687-688.

BRUGHA, T.S., Wing, J.K., BREWIN, C.R. et al (1989) Physical health of the long-term mentally ill in the community: is there unmet need? British Journal of Psychtatry. 165. 777-781.

Honig, A., POP, P., TAN, E.S. et al (1989) Physical illness in chronic psychiatric patients from a community psychiatric unit. Implications for dally practice. British Journal of Psychiatry, 165, 58-64.

HORDER. E. (1990) Medical Care in Three Psychlatric Hostels. London: Hampstead and South Barnet GP Forum and the Hampstead Department of Community Medicine.

Tony Kendrick, General Practitioner, Health Centre, Stepgates, Chertsey, Surrey KT16 8HZ and Sentor Lecturer, Division of General Practice and Primary Care, St George's Hospital Medical School, Cranmer Terrace, London SW17 ORE

\title{
Links between fund-holding general practices and mental health professionals
}

\author{
T. I. R. Mutale
}

\begin{abstract}
A postal questionnaire was sent to a random sample of 300 fund-holding general practices. Respondents were asked to indicate if they had links with a psychiatrist, community poychiatric nurse or psychologist, 210 (70\%) general practitioners retumed completed questionnaires. Out of 210 proctices 161 (77\%) had links with at least one speciallist mental health professional. Community poychlatric nurses had links with more practices than psychiatrists or psychologists. Problems with time or space made it dificult for practices to form links.
\end{abstract}

Patients with psychological disorders make up one fifth to a quarter of the workload of the average general practitioner (Shepherd et al, 1966). The recent shift of mental health resources to community-based care has led to a greater need for specialist input at primary care level. Some GPs have responded to this need by establishing links with mental health professionals (Thomas \& Corney, 1992). Fund-holding practices, who are direct purchasers in their own right, are in a powerful position to influence such links.
This study set out to determine the extent and quality of links between fund-holding practices and a broad range of specialist mental health professionals. Previous studies have determined links between GPs and mainly one type of profession (Brown \& Tower, 1990). Those that have looked at links with a wider range of professionals have not determined the quality of the links found, or made a distinction between child and adult mental health practitioners (Thomas \& Corney, 1992). This study remedies both these shortcomings. In addition, it is the first survey to study the impact of fund-holding on working relationships between mental health professionals and GPs.

\section{The study}

In May and June 1993, 300 general practices were chosen from a list of first wave and second wave fund-holding practices in the United Kingdom, using a random numbers table. One 
Table 1. Fund-holding practices: links with specialist mental health professionals

\begin{tabular}{llll}
\hline Professional & \multicolumn{3}{l}{ Number (\%) of practices ( $n=210)$ with: } \\
\cline { 2 - 4 } & $\begin{array}{l}\text { regular } \\
\text { meetings }\end{array}$ & $\begin{array}{l}\text { practice-based } \\
\text { clinics }\end{array}$ & $\begin{array}{l}\text { joint } \\
\text { assessment }\end{array}$ \\
\hline Adult psychiatrist & $37(17.6)$ & $71(33.8)$ & $7(3.3)$ \\
Child psychiatrist & $29(13.8)$ & $54(25.7)$ & $9(4.3)$ \\
Psychologist (Adult) & $27(12.9)$ & $89(42.4)$ & $4(1.9)$ \\
Psychologist (Child) & $21(10.0)$ & $61(29.1)$ & $4(1.9)$ \\
CPN (Adult) & $83(39.5)$ & $77(36.7)$ & $1(0.5)$ \\
CPN (Child) & $52(24.8)$ & $49(23.3)$ & $1(0.5)$ \\
\hline
\end{tabular}

Table 2. Fund-holding practices: overall links and face to face contact with specialist mental health professionals

\begin{tabular}{lll}
\hline Professionals & \multicolumn{2}{l}{ Number (\%) of contacts ( $n=210)$ with: } \\
\cline { 2 - 3 } & any link & face to face contact \\
\hline Adult and child psychiatrists & $119(56.7)$ & $51(24.3)$ \\
Adult and child psychologists & $118(56.2)$ & $29(13.8)$ \\
Adult and child CPNs & $152(72.4)$ & $86(41.0)$ \\
All adult professionals & $160(76.2)$ & $91(43.3)$ \\
All child professionals & $103(49.0)$ & $62(29.5)$ \\
\hline
\end{tabular}

GP was chosen, using a random numbers table from each of the 300 index practices. The 300 GPs were each sent a questionnaire, together with a personally addressed covering letter. A second questionnaire was sent to GPs who had not responded within three weeks.

GPs were asked if their practice had links with any of the following six professionals: adult psychiatrist, child psychiatrist, adult psychologist, child psychologist, community psychiatric nurse (adult) and community psychiatric nurse (child). Respondents were asked to indicate the nature of each link with a professional by ticking one of the following three categories: professional holds regular practice-based meeting with GPs at which patients are discussed; professional and GP assess patients jointly; professional holds practice-based clinics but does not involve or discuss cases with GP.

\section{Findings}

Out of 300 GPs, 210 (70\%) returned completed questionnaires.

Table 1 shows the existing links between fund-holding practices and six types of mental health professionals. Out of 210 practices, 161 (77\%) had links with at least one mental health professional.
Table 2 shows overall existing links and face to face contact with psychiatrists, psychologists, and community psychiatric nurses (CPNs). Face to face contact was defined as regular meetings with a professional or joint assessment of patients, with both characterised by GP and mental health professional coming face to face. Out of 210 practices, $90(43 \%)$ had face to face contact with at least one mental health professional. Out of 210 practices, $12(6 \%)$ held joint patient assessments with at least one mental health professional. Out of 210 GPs, 70 (33\%) commented that they did not have joint patient assessments because of restrictions on time and space.

\section{Comment}

This study shows that at least three-quarters of fund-holding practices have a link with a mental health professional. A recent study suggested that practices that had such links had an interest in psychological matters in that they were also more likely to employ counsellors (Thomas \& Corney, 1992). Such psychologically minded GPs may have to choose between counsellors and links with specialist mental health professionals if both are to be funded from the practice budget. They are likely to choose the cheaper option. 
That CPNs had links with the greatest number of practices is important because CPN attachment to primary care teams decreases the number of new and emergency referrals to hospital services (Wells et al, 1992).

The number of practices that had links with each of the following was higher than in Thomas \& Corney's study (1992): CPN (72\% v. 50\%); psychiatrist (57\% v. 16\%); and psychologist (56\% v. 15\%). This suggests that fund-holding practices actively seek more links with mental health professionals than other GPs.

That CPNs had face to face contact with more fund-holding practices than other professionals is important because face to face contact is probably one of the most effective ways of changing a GPs clinical behaviour (Grol, 1992). The CPN is, therefore, in a powerful position to influence clinical practice at primary care level. Similarly, adult professionals, who have more face to face contact than child professionals, are likely to have a greater influence on fund-holders priorities for mental health.

That only $6 \%$ of practices assessed patients jointly with a mental health professional contrasts with the enthusiasm for joint assessments shown in previous studies (Brown \& Tower, 1990). Comments by one third of respondents suggest that it is lack of time and space rather than of enthusiasm that prevents more joint assessments.

The study indicates that psychiatrists or psychologists who intend to establish links with fund-holders should note that the majority already have a link with a CPN. Time and space constraints may make it difficult for a practice that already has regular meetings or joint assessments with another professional to arrange extra meetings for a second or third professional. Regular multidisciplinary meetings may be one way of accommodating several professionals without increasing demands on time or space and would also provide an opportunity for mental health professionals and GPs to influence each other. Further research is required to determine the feasibility of such multidisciplinary links.

\section{References}

BROWN, L.M. \& TOWER, J.E.C. (1990) Psychiatrists in primary care: would general practitioners welcome them? Brttish Journal of General Practice, 40, 369-371.

GROL. R. (1992) Implementing guidelines in general practice care. Quality in Health Care, 1, 184-191.

SHEPHERd, M., COOPER. B., Brown, A. \& Kalton, G. (1966) Psychiatric Illness in General Practice. Oxford University Press.

THOMAS, R.V.R. \& CORNEY, R.H. (1992) A survey of links between mental health professionals and general practices in six district health authorities. Brittsh Journal of General Practice, 42, 358-361.

Wells, A.D.. Eagles, J.M., Hunter, D. \& Fowle, D.G. (1992) Changes in referral rates following community psychiatric nurse attachment to a primary care team. Psychiatric Bulletin, 16, 264-265.

T.I.R. Mutale, Senior Registrar in Child and Adolescent Psychiatry, Department of Psychological Medicine, Hospital for Sick Children, Great Ormond Street, London WC1 3JH 